\title{
Strategy for the Surgical Management of Insulinomas: Analysis of 52 Cases
}

\author{
Hong Liu ${ }^{a}$ Chenghong Peng ${ }^{c}$ Suzhan Zhang ${ }^{b}$ Yulian Wu ${ }^{a}$ Heqing Fang ${ }^{a}$ \\ Hongwei Sheng a Shuyou Peng ${ }^{c}$ \\ ${ }^{a}$ Department of Surgery and ${ }^{b}$ Cancer Institute, Second Affiliated Hospital, Zhejiang University School of Medicine, \\ Hangzhou, and 'Department of Surgery, Shanghai Ruijin Hospital, Shanghai Jiao Tong University School of \\ Medicine, Shanghai, China
}

\section{Key Words}

Benign insulinomas • Malignant insulinomas •

Surgical strategies, insulinomas

\begin{abstract}
Aim: The goal of this retrospective study was to analyze the strategy for the surgical management of insulinomas. Methods: From May 2000 to October 2006, the medical records of 52 patients with insulinomas were retrospectively studied. Results: All tumors were localized precisely by imaging techniques combined with intraoperative palpation. Forty-eight patients with benign lesions underwent surgical treatment: 41 patients open and 7 patients laparoscopic procedures. Four patients with malignant insulinomas underwent tumor resection; 3 of them underwent metastatic lesion and/or lymph node dissection. There were no discrepancies regarding operation time, blood loss, and complication rate between open enucleation and laparoscopic surgery. The mean hospital stay was $11.8 \pm 3.4$ days after laparoscopic surgery, shorter than the $17.0 \pm 6.0$ days after the open approach. Twenty-two complications occurred in 17 patients (32\%) following resection. On follow-up, $86 \%$ of the patients were free from symptoms, and surgical cure was achieved in 95\% of the patients with benign insulinomas. Conclusions: The choice of the surgical strategy for the treatment of pancreatic insulinomas depends on size and location of the tumor and the risk of malignancy. The optimal surgical pro-
\end{abstract}

\section{KARGER}

Fax +41613061234

E-Mail karger@karger.ch

www.karger.com (c) 2007 S. Karger AG, Basel

$0253-4886 / 07 / 0246-0463 \$ 23.50 / 0$

Accessible online at:

www.karger.com/dsu cedure is key to prevent postoperative complications. The laparoscopic approach is safe and feasible for patients with benign tumors located in body or tail of the pancreas.

Copyright $\odot 2007$ S. Karger AG, Basel

\section{Introduction}

Insulinomas are the most common functioning neuroendocrine tumors with an incidence of $0.8-0.9$ cases per million person-years in China. They occur in all age groups, and a female predominance of $60-70 \%$ is evident $[1,2]$. The majority of insulinomas are benign, solitary, and are located within the pancreatic parenchyma. Because of the characteristic clinical presentation of hypoglycemia, they usually are diagnosed, when they still are small $(<20 \mathrm{~mm}$ in size $)$ and resectable $[3,4]$. Approximately $10 \%$ of the insulinomas are malignant. The 10 year survival rate is estimated at 91 and 29\% for benign and malignant insulinomas, respectively. Surgical resection is preferred for insulinomas and achieved cure in more than $90 \%$ of the patients [5-7]. Surgical procedures include tumor enucleation, partial or total pancreatic resection, and pancreatoduodenectomy (Whipple's operation). If malignancy is suspected, metastatic tumor resection and/or lymph node dissection is mandatory $[8,9]$. In recent years, laparoscopic resection of pancreatic insulinomas has been performed successfully and provides pa-

Dr. Suzhan Zhang

Cancer Institute, Second Affiliated Hospital

Zhejiang University School of Medicine, 88 Jiefang Road

Hangzhou 310006 (China)

Tel. +86 5718778 4528, Fax +86 5718702 2776, E-Mail zhangscy@tom.com 

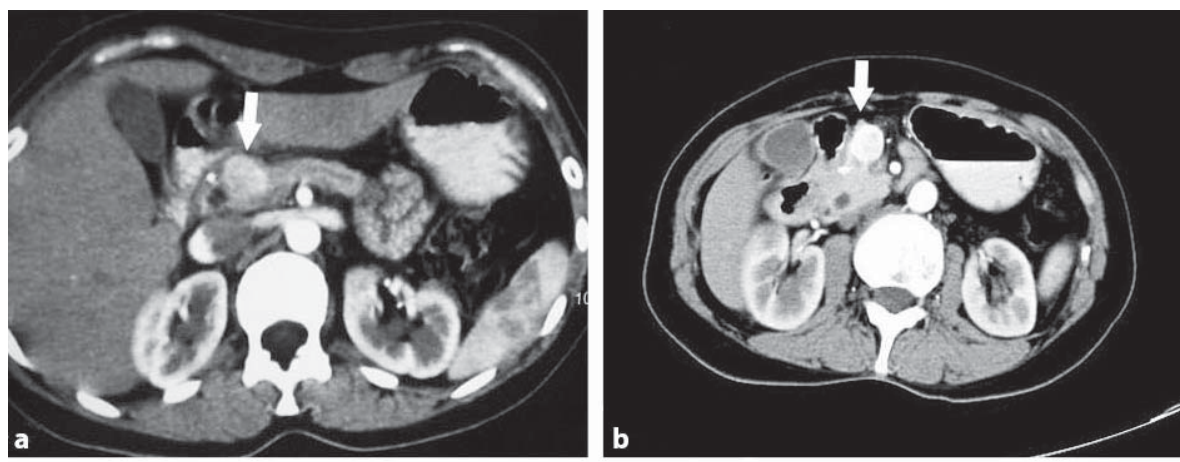

Fig. 1. Computed tomography scans showing lesions (arrows). a Lesion in the head of the pancreas. $\mathbf{b}$ Lesion in the neck of the pancreas. c Lesion in the tail of the pancreas. d Metastatic lesion of the liver.
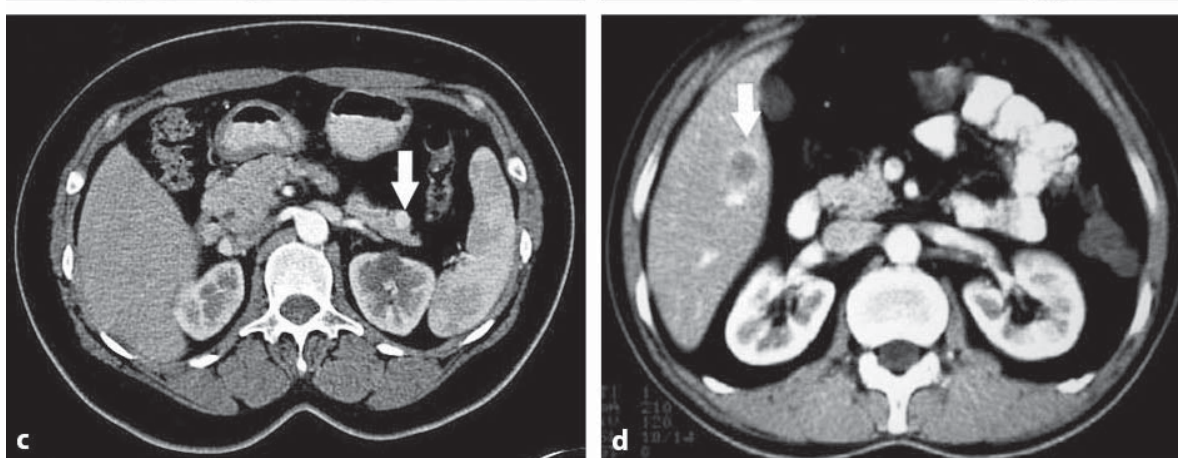

tients with the benefits of minimally invasive surgery [10-12]. However, only a few authors have reported the management strategy of insulinoma resection. The goal of this retrospective study was to assess feasibility, safety, and outcome of different surgical approaches and to analyze the surgical strategy of insulinoma management.

\section{Patients and Methods}

From May 2000 to October 2006, the data of 52 patients with pancreatic insulinomas were retrospectively collected for the present study. These patients included 19 men and 33 women with a mean age of $47 \pm 13$ (range 16-76) years who underwent surgical treatment at the Second Affiliated Hospital of the Zhejiang University (Hangzhou) and the Ruijin Hospital of the Jiao Tong University (Shanghai). All patients presented with hypoglycemia that developed after fasting or exertion and improved after glucose intake. The diagnosis was confirmed with a 75 -gram oral glucose tolerance test and determination of serum insulin, proinsulin, and $\mathrm{C}$ peptide levels every $6 \mathrm{~h}$. Preoperative localization was performed, including transabdominal ultrasonography, computed tomography, magnetic resonance imaging, selective arteriography, and endoscopic ultrasonography. Furthermore, intraoperative ultrasonography and intraoperative frozen-section examination were also performed routinely in order to verify their diagnostic yield.

The results are expressed as mean values $\pm \mathrm{SD}$. Independent sample t test and ANOVA were used to compare quantitative variables. Significance was defined as $\mathrm{p}<0.05$.

\section{Results}

Localization of the Lesion

All patients underwent at least one of the above-mentioned imaging procedures to localize the lesions. The sensitivity was $77 \%$ for computed tomography $(\mathrm{n}=35)$, $55 \%$ for ultrasonography $(n=31), 64 \%$ for selective arteriography $(\mathrm{n}=14), 73 \%$ for magnetic resonance imaging $(\mathrm{n}=11), 88 \%$ for endoscopic ultrasonography $(\mathrm{n}=16)$, and $95 \%$ for intraoperative utrasonography $(n=19)$. All tumors were precisely located according to previously mentioned imaging techniques. Sixteen lesions (30\%) were localized in the head, two (4\%) in the uncinate process, four (8\%) in the neck, 17 (32\%) in the body, and 14 $(26 \%)$ in the tail of the pancreas (fig. 1a-c). Mean sizes of the lesions were $15.7,17.4,14.2,16.9$, and $15.1 \mathrm{~mm}$ in head, uncinate process, neck, body, and tail of the pancreas, respectively. Moreover, a metastatic liver lesion was identified by computed tomography (fig. 1d), and a metastatic porta hepatis lesion was identified by ultrasonography (fig. 2).

\section{Surgical Management}

Table 1 summarizes the surgical features of the patients with benign insulinomas. The open surgical procedures were performed in 41 patients. Successful laparoscopic re- 

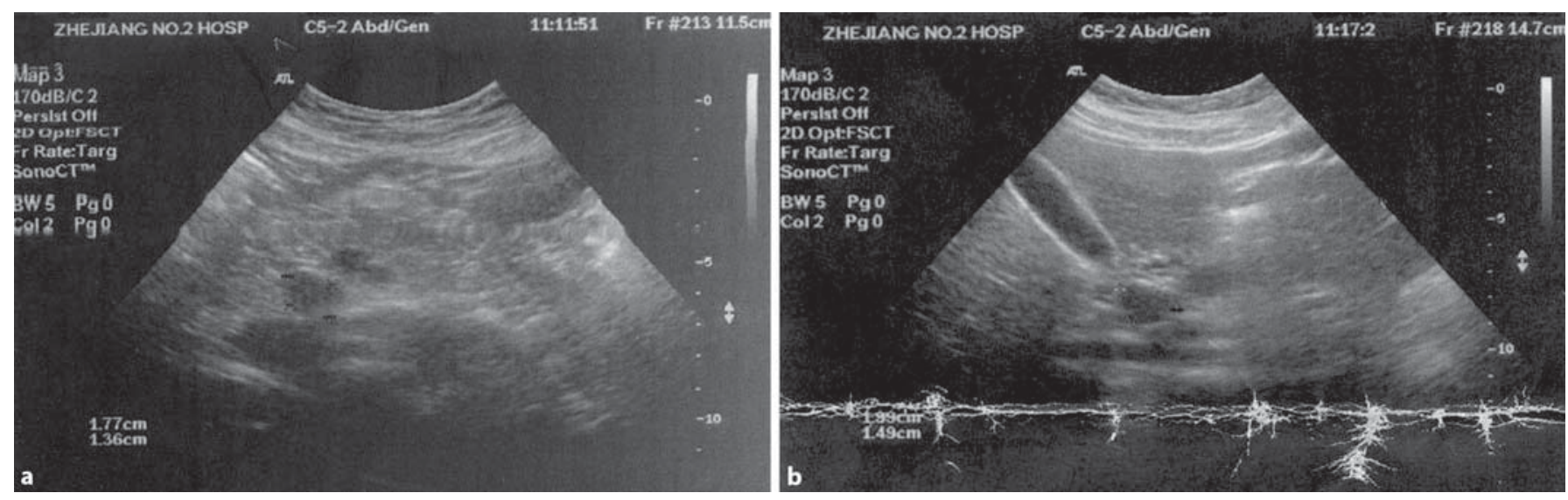

Fig. 2. Ultrasonography scans. a Lesion in the head of the pancreas. Size $1.77 \times 1.36 \mathrm{~cm}$. b Metastatic lesion in the porta hepatis. Size $1.99 \times 1.49 \mathrm{~cm}$.

Table 1. Surgical features of 48 patients with benign insulinomas

\begin{tabular}{|c|c|c|c|c|c|c|}
\hline Surgical procedure & $\mathrm{n}$ & Location & $\begin{array}{l}\text { Tumor size } \\
\mathrm{mm}\end{array}$ & $\begin{array}{l}\text { Operation time } \\
\text { min }\end{array}$ & $\begin{array}{l}\text { Blood loss } \\
\mathrm{ml}\end{array}$ & $\begin{array}{l}\text { Hospital stay } \\
\text { days }\end{array}$ \\
\hline Open surgery & 41 & - & $15.4 \pm 3.1$ & $154 \pm 48$ & $174 \pm 163$ & $18.5 \pm 6.7$ \\
\hline Enucleation & 26 & $\mathrm{H}(12), \mathrm{B}(9), \mathrm{T}(5)$ & $14.7 \pm 2.9$ & $127 \pm 23$ & $91 \pm 46$ & $17.0 \pm 6.0$ \\
\hline Distal pancreatectomy & 7 & $\mathrm{~B}(3), \mathrm{T}(5)^{\mathrm{a}}$ & $16.6 \pm 3.0$ & $177 \pm 32$ & $246 \pm 59$ & $18.4 \pm 5.7$ \\
\hline Central pancreatectomy & 5 & $\mathrm{~N}(3), \mathrm{H}(2)$ & $15.6 \pm 3.3$ & $212 \pm 35$ & $190 \pm 42$ & $21.0 \pm 8.3$ \\
\hline Pancreatoduodenectomy & 3 & $\mathrm{H}(1), \mathrm{U}(2)$ & $18.7 \pm 3.5$ & $247 \pm 35$ & $667 \pm 66$ & $27.3 \pm 7.1$ \\
\hline Laparoscopic surgery & 7 & $\mathrm{~B}(4), \mathrm{T}(3)$ & $15.2 \pm 2.8$ & $159 \pm 21$ & $77 \pm 50$ & $11.8 \pm 3.4^{* *}$ \\
\hline
\end{tabular}

$\mathrm{H}=$ Head; $\mathrm{B}=$ body $; \mathrm{T}=$ tail $\mathrm{N}=$ neck; $\mathrm{U}=$ uncinate process.

a One patient had two lesions. ${ }^{* *} \mathrm{p}=0.01$ as compared with open enucleation.

section was performed in 7 out of 10 selected patients, 6 patients underwent tumor enucleation, and 1 patient underwent spleen-preserving distal pancreatectomy. Three conversions to open surgery were required because of inability to identify the tumor. Excluding the patients who had conversion to laparotomy, there were no discrepancies with regard to operation time and blood loss between open enucleation and laparoscopic surgery. The mean hospital stay was $11.8 \pm 3.4$ days after laparoscopic surgery, shorter than the $17.0 \pm 6.0$ days after the open approach $(\mathrm{p}=$ 0.01). Pancreatoduodenectomy needed longer operating times and hospital stays and caused greater blood loss as compared with the other surgical procedures.

Four patients with malignant insulinomas underwent successful removal of the primary tumor, including three distal pancreatectomies and one pancreatoduodenectomy. Moreover, wedge resection of the liver was performed in 2 patients, lymph node dissection in 1 patient, and he-

Surgical Strategy for the Treatment of Insulinomas patic arterial chemoembolization was performed in 1 patient with hepatic islet cell metastases.

\section{Morbidity}

There were no operative deaths. Twenty-two complications occurred in 17 patients (32\%) following resection (table 2). The morbidity was $28 \%$ for Laparoscopic surgery and 36\% for open surgery (nonsignificant difference). The most common complications were pancreatic fistulas, delayed gastric emptying, and infections. Other complications included intra-abdominal collection ( $\mathrm{n}=$ $3)$, pleural effusion $(n=2)$, pancreatic pseudocyst $(n=1)$, bleeding $(\mathrm{n}=1)$, and diabetes $(\mathrm{n}=1)$. Two patients required reoperation during the early postoperative period: 1 for intra-abdominal bleeding and 1 for severe pancreatic fistula. Five low-output pancreatic fistulas spontaneously healed after 6 weeks. One patient who underwent pancreatectomy developed late diabetes. 
Table 2. Postoperative complications in patients with insulinomas

\begin{tabular}{lllllr}
\hline Surgical procedure & $\begin{array}{l}\text { Pancreatic } \\
\text { fistula }\end{array}$ & $\begin{array}{l}\text { Delayed gastric } \\
\text { emptying }\end{array}$ & Infections & $\begin{array}{l}\text { Other } \\
\text { complications }\end{array}$ & $\begin{array}{l}\text { Number of } \\
\text { patients }\end{array}$ \\
\hline $\begin{array}{l}\text { Laparoscopic surgery } \\
\text { Open surgery }\end{array}$ & 1 & & & 1 & 2 \\
$\quad$ Enucleation & 5 & 5 & 3 & 7 & 15 \\
$\quad \begin{array}{l}\text { Distal pancreatectomy } \\
\quad \text { Central pancreatectomy }\end{array}$ & 1 & 2 & 1 & 3 & 7 \\
$\quad$ Pancreatoduodenectomy & & 2 & 1 & 2 & 3 \\
\hline Total & 6 & 5 & 1 & 2 & 2 \\
\hline
\end{tabular}

\section{Follow-Up}

Follow-up data were obtained from patient records supplemented with a mailed questionnaire. The patients were considered cured postoperatively, if symptoms disappeared and serum hormone levels were normal and remained so for at least 6 months. Seven patients had been lost to follow-up, and 1 patient died of diffuse liver metastases of the malignant insulinoma 3 years after primary operation. During the median follow-up period of 37 (range 6-61) months, 38 patients (86\%) were free from symptoms. Surgical cure was achieved in $95 \%$ of the patients (39/41) with benign insulinomas.

\section{Discussion}

Surgery is the only curative option for neuroendocrine tumors, and surgical cure of benign insulinomas was achieved in more than $90 \%$ of the patients [13]. Recent guidelines for the management of neuroendocrine tumors suggest that all patients should be sent to an experienced endocrine surgeon [14].

Generally, insulinomas of the pancreas are evenly distributed over the entire gland. Either enucleation or distal pancreatectomy is used for lesions located in body or tail of the pancreas; enucleation is indicated for small, benign lesions located at least $2-3 \mathrm{~mm}$ from the main pancreatic duct [7]. Intraoperative ultrasonography and intraductal ultrasonography can be used to measure the distance between tumor margin and main pancreatic duct [15-17]. In our study, open surgery was performed in 21 patients with tumors located in body or tail of the pancreas: 14 enucleations and 7 distal resections. Pancreatic leakage developed after enucleation in 1 patient because of injury of the main pancreatic duct, requiring a distal pancreatectomy with salvage splenectomy 2 months after the initial operation. It was reported $[18,19]$ that patients who undergo distal pancreatectomy and splenectomy have significantly more postoperative complications, in particular infections, than patients who have a spleenpreserving procedure.

With advances in laparoscopic techniques, an increasing number of successful laparoscopic resections for insulinomas is reported in the literature [10-12, 20-27]. In 7 of our patients undergoing successful laparoscopic resection, the tumors were located in body or tail of the pancreas. The conversion rate was 30\% (3/10), the main cause was inability to identify the tumor. There were no discrepancies with regard to operation time, blood loss, and complication rate between open enucleation and laparoscopic surgery. The mean hospital stay was $11.8 \pm 3.4$ days after laparoscopic surgery, shorter than the $17.0 \pm 6.0$ days after open surgery. In accordance with reviews of the literature, we believe that the laparoscopic approach is feasible and safe, although good skills were required as well as preoperative localization of the tumor and definition of its nature. Patients with benign tumors located in body or tail of the pancreas can better benefit from the laparoscopic approach which provides faster postoperative recovery and comparable morbidity rates in comparison with patients undergoing open surgery $[11,26,27]$. Laparoscopic ultrasonography is highly sensitive to locate insulinomas and probably to prevent conversion [28].

Nonenucleable benign pancreatic lesions located in neck or adjacent body of the pancreas (pancreatic isthmus) are traditionally treated with pancreatoduodenectomy or distal pancreatectomy. Since the traditional pancreatic resection resulting in substantial loss of normal pancreatic parenchyma with an unnecessary risk of pancreatic endocrine/exocrine insufficiency and splenic loss, several authors have described central pancreatectomy as an alternative to the standard pancreatic resection [29- 

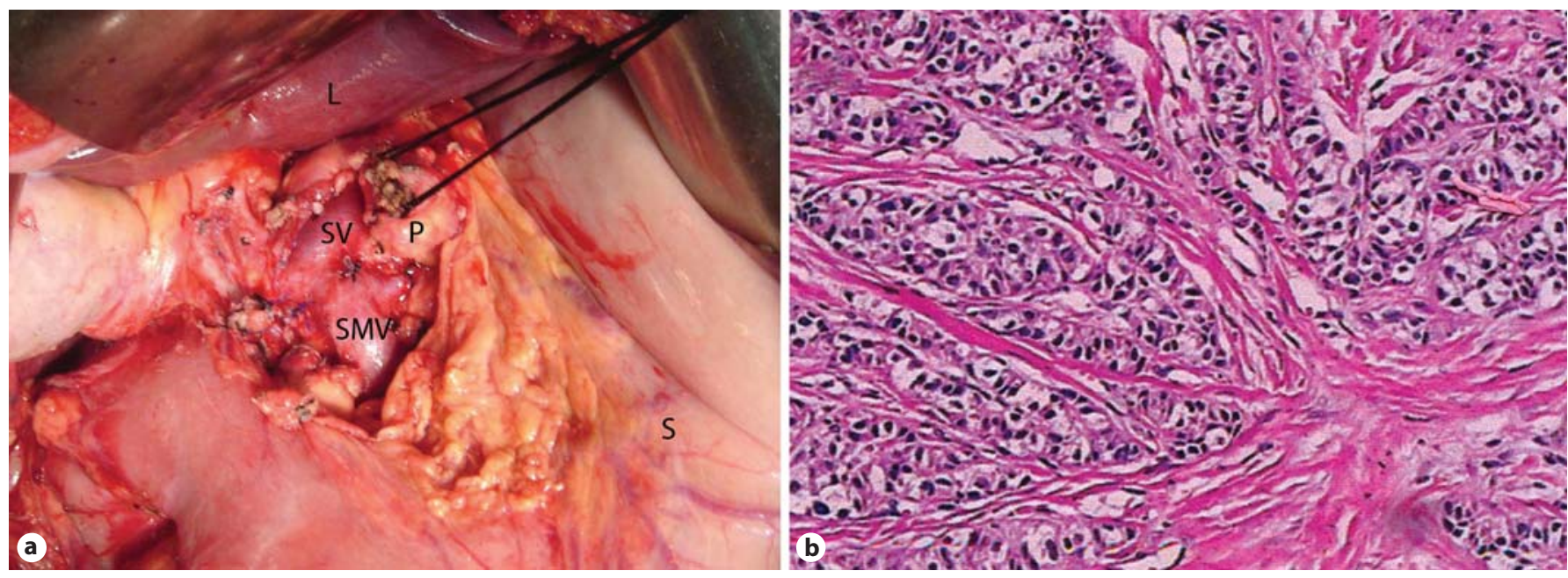

Fig. 3. a Central pancreatectomy. $L=$ Liver; $S V=$ splenic vein; $P=$ pancreas; $S M V=$ superior mesenteric vein; $\mathrm{S}=$ stomach. $\mathbf{b}$ Pathology: borderline insulinoma.

32]. In our study, five central pancreatectomies were successfully performed (fig. 3). The cephalic pancreatic stump is oversewn, and the distal stump is anastomosed end-toend with a Roux-en-Y jejunal loop by binding pancreatojejunostomy [33, 34]. At follow-up, no patients who underwent central pancreatectomy developed late diabetes.

Open enucleation is the procedure of choice for tumors located in head or uncinate process of the pancreas, because the laparoscopic approach is technically difficult $[21,35]$. Resection may be required, when the tumor is located deep in the pancreatic head parenchyma and/or abuts pancreatic duct or major vessels. Resection options include Whipple's procedure and duodenum-preserving pancreatic head resection. In our study, 16 lesions were localized in head or uncinate processes of the pancreas; 12 of them were enucleated and the other 4 removed by pancreatectomy. To determine completeness of the tumor excision, a perioperative insulin assay may be valuable [36].

Malignant insulinomas invade locally into surrounding soft tissue or structures and also spread by lymph node or liver metastases. Patients with a malignant insulinoma should undergo formal pancreatic resection. An aggressive approach is recommended in the presence of metastatic disease; if appropriate, surgery should be combined with lymph node dissection and/or hepatic tumor reduction [7, 8, 37]. Of our 4 patients, 3 are alive, and 1 survived for more than 3 years. A proven effect on survival cannot be concluded from this study because of the small number of patients. Danforth et al. [38] demonstrated a median disease-free survival after curative re- section of 5 years, with a recurrence rate of $63 \%$. After initial surgical resection, the biology of the tumor, rather than any treatment modality, was most likely the major determinant of the long-term survival [8].

Although the mortality rate of pancreatic surgery has been reduced in recent years, the postoperative morbidity still shows a high incidence; $32 \%$ of our patients developed postoperative morbidity, including 6 pancreatic fistulas. Pancreatic leakage is one of the most frequent complications after insulinoma resection. Therefore, several surgical techniques and several devices for the management of pancreatic ducts have been advocated to prevent pancreatic leakage. In our experience, it is important to determine the optimal resection procedure with respect to the proximity of the tumor to the main pancreatic duct. On the other hand, the pancreatic duct should be identified and directly ligated during pancreatectomy [39]. Recently, Kuroki et al. [40] reported a novel surgical technique, a gastric-wall-covering method, for the prevention of pancreatic leakage.

In conclusion, the surgical strategy for pancreatic insulinomas depends on size and location of the tumor and on the risk of malignancy. The optimal surgical procedure is key to prevent postoperative complications. Blind pancreatic resection in the absence of preoperative tumor localization is not recommended. Laparoscopic surgery is safe and feasible for patients with benign tumors located in body or tail of the pancreas. Radical resection, including initial and metastatic lesions, may benefit patients with malignant insulinomas. 


\section{References}

-1 Service FJ, McMahon MM, O’Brien PC, Ballard DJ: Functioning insulinoma - incidence, recurrence, and long-term survival of patients: a 60-year study. Mayo Clin Proc 1991;66:711-719.

-2 Boukhman MP, Karam JH, Shaver J, Siperstern AE, Duh QY, Clark OH: Insulinoma: experience from 1950 to 1995 . West J Med 1998;169:98-104.

3 Perry RR, Vinik AI: Clinical review 72: diagnosis and management of functioning islet cell tumors. J Clin Endocrinol Metab 1995; $80: 2273-2278$

4 Delcore R, Friesen SR: Gastrointestinal neuroendocrine tumors. J Am Coll Surg 1994; 178:187-211.

$\checkmark 5$ Doherty GM, Doppman JL, Shawker TH, Miller DL, Eastman RC, Gorden P, Norton JA: Results of a prospective strategy to diagnose, localize, and resect insulinomas. Surgery 1991;110:989-996.

6 Soga J, Yakuwa Y, Osaka M: Insulinoma/hypoglycemic syndrome: a statistical evaluation of 1085 reported cases of a Japanese series. J Exp Clin Cancer Res 1998;17: 379-388.

7 Finlayson E, Clark OH: Surgical treatment of insulinomas. Surg Clin North Am 2004;84: 775-785.

$\checkmark 8$ Hirsberg B, Cocran C, Skarulis MC, Libutti SK, Alexander HR, Wood BJ, Chang R, Kleiner DE, Gorden P: Malignant insulinoma: spectrum of unusual clinical features. Cancer 2005; 104:264-272.

9 Sarmiento JM, Que FG, Grant CS, Thompson GB, Farnell MB, Nagorney DM: Concurrent resections of pancreatic islet cell cancers with synchronous hepatic metastases: outcomes of an aggressive approach. Surgery 2002;132:976-982.

10 Mabrut JY, Fernandez-Cruz L, Azagra JS, Bassi C, Delvaux G, Weerts J, Fabre JM, Boulez J, Baulieux J, Peix JL, Gigot JF; Hepatobiliary and Pancreatic Section (HBPS) of the Royal Belgian Society of Surgery; Belgian Group for Endoscopic Surgery (BGES); Club Coelio: Laparoscopic pancreatic resection: results of a multicenter European study of 127 patients. Surgery 2005;137:597-605.

-11 Sa Cunha A, Beau C, Rault A, Catargi B, Collet D, Masson B: Laparoscopic versus open approach for solitary insulinoma. Surg Endosc 2007;21:103-108.

12 Fernandez-Cruz L, Cesar-Borges G: Laparoscopic strategies for resection of insulino mas. J Gastrointest Surg 2006;10:752-760.

-13 Matthews BD, Smith TI, Kercher KW, Holder WD Jr, Heniford BT: Surgical experience with functioning pancreatic neuroendocrine tumors. Am Surg 2002;68:660665.

14 Ramage JK, Davies AH, Ardill J, Bax N, Caplin M, Grossman A, Hawkins R, McNicol AM, Reed N, Sutton R, Thakker R, Ayl- win S, Breen D, Britton K, Buchanan K, Corrie $\mathrm{P}$, Gillams A, Lewington $\mathrm{V}$, McCance D, Meeran K, Watkinson A; UKNETwork for Neuroendocrine Tumours: Guidelines for the management of gastroenteropancreatic neuroendocrine (including carcinoid) tumours. Gut 2005;54(Suppl 4):iv1-16.

15 Hiramoto JS, Feldstein VA, LaBerge JM, Norton JA: Intraoperative ultrasound and preoperative localization detects all occult insulinomas. Arch Surg 2001;136:10201026.

16 Yamao K, Okubo K, Sawaka A, Hara K, Nakamura T, Suzuki T, Shimizu Y, Ozden I: Endoluminal ultrasonography in the diagnosis of pancreatic diseases. Abdom Imaging 2003;28:545-555.

17 Menzel J, Domschke W: Intraductal ultrasonography may localize islet cell tumours negative on endoscopic ultrasound. Scand J Gastroenterol 1998;33:109-112.

18 Shoup M, Brennan MF, McWhite K, Leung $\mathrm{DH}$, Klimstra D, Conlon KC: The value of splenic preservation with distal pancreatectomy. Arch Surg 2002;137:164-168.

19 Giovanardi RO, Giovanardi HJ, Fontana CA, Kuhn F, Kalil AN: Laparoscopic distal pancreatectomy for insulinoma with preservation of the spleen. Hepatogastroenterology 2005;52:261-263.

20 Gagner M, Pomp A, Herrera MF: Early experience with laparoscopic resections of islet cell tumors. Surgery 1996;120:1051-1054.

-21 Berends FJ, Cuesta MA, Kazemier G, van Eijck CH, de Herder WW, van Muiswinkel JM, Bruining HA, Bonjer HJ: Laparoscopic detection and resection of insulinomas. Surgery 2000;128:386-391.

22 Gramatica L Jr, Herrera MF, Mercado-Luna A, Sierra M, Verasay G, Brunner N: Videolaparoscopic resection of insulinomas: experience in two institutions. World J Surg 2002; 26:1297-1300.

23 Jaroszewski DE, Schlinkert RT, Thompson GB, Schlinkert DK: Laparoscopic localization and resection of insulinomas. Arch Surg 2004; 139:270-274.

24 Ayav A, Bresler L, Brunaud L, Boissel P; SFCL (Société Française de Chirurgie Laparoscopique); AFCE (Association Francophone de Chirurgie Endocrinienne): Laparoscopic approach for solitary insulinoma: a multicentre study. Langenbecks Arch Surg 2005;390:134-140.

25 Fernández-Cruz L, Martínez I, Cesar-Borges G, Astudillo E, Orduña D, Halperin I, Sesmilo G, Puig M: Laparoscopic surgery in patients with sporadic and multiple insulinomas associated with multiple endocrine neoplasia type 1. J Gastrointest Surg 2005;9: 381-388.

26 Minni F, Marrano N, Pasquali R: Laparoscopic body-tail pancreatic resection for insulinoma. Surg Endosc 2003;17:159-160.
27 Toniato A, Meduri F, Foletto M, Avogaro A, Pelizzo M: Laparoscopic treatment of benign insulinomas localized in the body and tail of the pancreas: a single-center experience. World J Surg 2006;30:1916-1919.

28 Lo CY, Lo CM, Fan ST: Role of laparoscopic ultrasonography in intraoperative localization of pancreatic insulinoma. Surg Endosc 2000;14:1131-1135.

29 Celis J, Berrospi F, Ruiz E, Payet E, Luque C: Central pancreatectomy for tumors of the neck and body of the pancreas. J Surg Oncol 2001;77:132-135.

30 Goldstein MJ, Toman J, Chabot JA: Pancreaticogastrostomy: a novel application after central pancreatectomy. J Am Coll Surg 2004;198:871-876.

31 Efron DT, Lillemoe KD, Cameron JL, Yeo CJ: Central pancreatectomy with pancreaticogastrostomy for benign pancreatic pathology. J Gastrointest Surg 2004;8:532-538.

32 Johnson MA, Rajendran S, Balachandar TG, Kannan DG, Jeswanth S, Ravichandran P: Central pancreatectomy for benign pancreatic pathology/trauma: is it a reasonable pancreas-preserving conservative surgical strategy alternative to standard major pancreatic resection? ANZ J Surg 2006;76:987995.

33 Peng SY, Mou YP, Liu YB, Su Y, Peng CH, Cai XJ, Zhou LH: Binding pancreaticojejunostomy: 150 consecutive cases without leakage. J Gastrointest Surg 2003;7:898-900.

34 Peng SY, Mou YP, Cai XJ, Peng CH: Binding pancreaticojejunostomy is a new technique to minimize leakage. Am J Surg 2002;183: 283-285.

35 Iihara M, Kanbe M, Okamoto T, Ito Y, Obara T: Laparoscopic ultrasonography for resection of insulinomas. Surgery 2001;130:10861091.

36 Carneiro DM, Levi JU, Irvin GL III: Rapid insulin assay for intraoperative confirmation of complete resection of insulinomas. Surgery 2002;132:937-942.

37 Sarmiento JM, Que FG: Hepatic surgery for metastases from neuroendocrine tumors. Surg Oncol Clin N Am 2003; 12:231-242.

38 Danforth DN Jr, Gorden P, Brennan MF: Metastatic insulin-secreting carcinoma of the pancreas: clinical course and the role of surgery. Surgery 1984;96:1027-1037.

39 Bilimoria MM, Cormier JN, Mun Y, Lee JE, Evans DB, Pisters PW: Pancreatic leak after left pancreatectomy is reduced following main pancreatic duct ligation. Br J Surg 2003; 90:190-196.

40 Kuroki T, Tajima Y, Tsutsumi R, Mishima T, Kitasato A, Adachi T, Kanematsu T: Intraoperative pancreatography and gastric-wallcovering method for the prevention of pancreatic leakage after enucleation of insulinoma in the pancreas. J Hepatobiliary Pancreat Surg 2006;13:314-316. 


\title{
Invited Commentary
}

\author{
Laureano Fernández-Cruz
}

Chair, Department of Surgery, Hospital Clínic de Barcelona, Barcelona, Spain

This report presents 52 patients with insulinoma collected during a 5 -year period. In this large series, 48 patients had benign lesions, and 4 had malignant insulinomas. Different imaging modalities were used for tumor localization: computed tomography, ultrasonography, selective arteriography, magnetic resonance imaging, and endoscopic ultrasonography. Computed tomography (performed in 35 patients) and endoscopic ultrasonography (performed in 16 patients) showed a sensitivity of $77 \%$ and one of $88 \%$, respectively. At the present time, based on the cost-benefit ratio, only computed tomography and endoscopic ultrasonography achieve the highest diagnostic sensitivity $(100 \%$ when both procedures are combined) and should replace other methods. However, under particular circumstances, arterially stimulated venous sampling may be required for an accurate regionalization (not localization). Recently, magnetic resonance imaging has shown excellent results for tumor localization. In addition, magnetic resonance imaging provides information in delineating the anatomic relationship of the tumor to the pancreatic duct. The accuracy of these imaging modalities, computed tomography, endoscopic ultrasonography, and magnetic resonance imaging, is essential for planning the surgical strategies in the management of insulinomas.

In this report, open surgery was performed in $41 \mathrm{pa}-$ tients, and 10 patients were selected for laparoscopic surgery. The authors did not state the criteria for one or an-

\section{Invited Commentary}

Volker Fendrich, Matthias Rothmund

Department of Surgery, Philipps University, Marburg, Germany

Insulinomas are rare tumors, estimated to occur with a frequency of 4 per million people. Of these cases, only $10 \%$ occur as part of the multiple endocrine neoplasia type I syndrome, and about $10 \%$ are malignant $[1,2]$.

The authors present a retrospective study, describing 52 patients with organic hyperinsulinism managed over

Surgical Strategy for the Treatment of Insulinomas other surgical approach. Independently of the surgical approach used, in our opinion, the authors have chosen the best decision for their patients: to enucleate the tumor in 26 of 41 patients. In a recent report from the Mayo Clinic [C. Grant, personal commun.], of 149 patients, 88 (59\%) underwent enucleation and 57 (38\%) distal pancreatic resection, both procedures performed by open surgery.

We believe that benign insulinomas should be approached laparoscopically as the first choice: the tumors are usually $<2 \mathrm{~cm}$ in diameter and can be localized anywhere in the pancreas with the help of laparoscopic ultrasound. Laparoscopic ultrasound also facilitates operative decision-making. The information helps the surgeon to choose between enucleation (in an attempt to preserve healthy pancreatic parenchyma) or resection and whether an anterior or posterior approach would help to avoid injury of the pancreatic duct or large blood vessels. The reported success for laparoscopic resection of insulinomas ranges from 60 to $100 \%$.

The authors should be congratulated on the low morbidity achieved in the group of patients operated on by open (36\%) or laparoscopic (28\%) approach. A point of concern was the length of hospital stay, a mean of 18.5 days after open surgery and of 11.8 days after laparoscopic surgery. This prolonged hospitalization increases the hospital costs and obscures the advantages of an adequate performance of a surgical procedure or the benefits of a minimally invasive approach.

a 6-year period in their centers. The number of patients treated with this rare disease during this short period of time is impressive.

Although a rare tumor, an overall cure rate of $>95 \%$ has been achieved in endocrine surgical centers, and recently laparoscopic resection of insulinomas has been 
reported. Laparoscopic pancreatic resection and laparoscopic enucleation are feasible and safe techniques in experienced hands [3]. The authors performed laparoscopic resection in 10 'selected' patients. Unfortunately, the criteria for this selection are not mentioned in the article. We and others think that insulinomas are suitable for a laparoscopic approach, if they are solitary, benign, and at well-accessible sites. The tumor should be localized preoperatively, mainly by endoscopic ultrasound [4]. Furthermore, the tumor should not be lying deep in the pancreatic head or close to the main pancreatic duct. Laparoscopic ultrasound must be available. In the study presented, successful laparoscopic resection was performed in 7 of 10 selected patients, 6 had tumor enucleation, and 1 patient had spleen-preserving distal pancreatectomy. The conversions were due to unidentified tumors. There were no differences in operation time, blood loss, or complication rate between open enucleation and laparoscopic resection, but the mean hospital stay was 6 days shorter after laparoscopic surgery. This is in line with results of a small series of own patients, a meta-analysis, and two multicentric studies [5-8].

The advantages of laparoscopic pancreatic procedures should be those of all laparoscopic procedures which obviously reduce the parietal damage in the abdomen. Small insulinomas can be treated effectively by either laparoscopic enucleation or laparoscopic pancreatic resection, and surgical cure can be achieved in most patients. It is to be expected that this approach will receive increasing attention in the near future.

\section{References}

1 Rothmund M, Angelini L, Brunt LM, et al: Surgery for benign insulinoma: an international review. World J Surg 1990;14:393-398.

2 Fendrich V, Langer P, Celik I, et al: An aggressive surgical approach leads to long-term survival in patients with pancreatic endocrine tumors. Ann Surg 2006;244:845-851.

3 Fernandez-Cruz L, Cesar-Borges G: Laparoscopic strategies for resection of insulinomas. J Gastrointest Surg 2006;10:752-760.

4 Kann PH, Rothmund M, Zielke A: Endoscopic ultrasound imaging of insulinomas: limitations and clinical relevance. Exp Clin Endocrinol Diabetes 2005;113:471-474.

5 Langer P, Bartsch DK, Fendrich V, et al: Minimal-invasive operative treatment of organic hyperinsulinism (in German). Dtsch Med Wochenschr 2005;130:514-518.

6 Assalia A, Gagner M: Laparoscopic pancreatic surgery for islet cell tumors of the pancreas. World J Surg 2004;28:1239-1247.

7 Ayav A, Bresler L, Brunaud L, Boissel P; SFCL (Société Française de Chirurgie Laparoscopique); AFCE (Association Francophone de Chirurgie Endocrinienne): Laparoscopic approach for solitary insulinoma: a multicentre study. Langenbecks Arch Surg 2005;390:134140 .

8 Mabrut JY, Fernandez-Cruz L, Azagra JS, et al: Laparoscopic pancreatic resection: results of a multicenter European study of 127 patients. Surgery 2005; 137:597-605. 